\title{
Multiple factor comprehensive analysis (CAMF) model of occupational health and safety training effect for construction workers
}

\author{
Zhonghong Cao*, Tao Chen **, Yuqing Cao***
}

* School of Economics and Management, Hunan University of Science and Engineering, Yongzhou 425199, Hunan, P.R.China, Professor, Ph.D

* Wuhan University of Science and Technology, Wuhan 4300081, Hubei, P.R.China, Professor, Ph.D, 917735337@qq.com

*** Department of Electrical Engineering, Columbia University, New York, New York 10027, USA, $1249053233 @$ qq.com

* Corresponding: E-mail address 418402664@qq.com(Z.Cao)

ORCID

Zhonghong Cao: https://orcid.org/0000-0002-1967-940X

\begin{abstract}
In view of the occupational health and safety (OHS) training on the safety of construction workers, and many complex factors. Through empirical investigation, this study proposes a set of multiple factor comprehensive analysis (CAMF) model to explore the effectiveness of OHS training and its main influencing factors. It has been found that training
\end{abstract}


effectiveness is positively related to whether to receive OHS training or not and also positively related to training methods. It has also been found that the effectiveness of training is positively related to the importance of post responsibility. The results show that the construction industry needs to strengthen the OHS system training of grass-root workers, and the training should be classified and graded according to the workers' educational backgrounds, training methods, job satisfaction, and job responsibilities. In the safety training management of on-site workers, salary is the basic factor, and more attention should be paid to the factors such as workers' physical safety, training and learning, and future career development. The empirical results show that CAMF model has certain practical significance. The research results can provide paths and suggestions for improving the effectiveness of OHS training in China's construction industry, and provide some reference for other developing countries to carry out OHS training.

Keywords: construction workers, occupational health and safety (OHS), training effect, CART, comprehensive analysis

\section{INTRODUCTION}

According to statistics, in China, there are about 3000 construction workers injured and killed every year (Loosemore \& Malouf, 2019). With the entry of Chinese construction enterprises into the international competitive market, the health and safety risks of foreign field workers have also increased sharply (Lei et al., 2018; Qammaz \& AlMaian, 2020). 
Therefore, the construction of occupational risks, especially the OHS injury risks of construction site workers, have attracted more and more attention from construction enterprise managers (Al-Salahi, Naji, \& Gunduz, 2020; Timofeeva, Ulrikh, \& Tsvetkun, 2017; Tremblay \& Badri, 2018). Unsafe behavior of construction workers is the main factor of accident injury (Guo, He, Li, \& Tang, 2020). The effective intervention of OHS-MS can improve active safety behavior (Mei, Wang, Liu, Zhou, \& Zhang, 2020). Accordingly, it has become the focus of risk management for construction enterprises to reduce the number of deaths in construction accidents and ensure the OHS of construction workers, by strengthening the OHS training and improving the training effect of the OHS of Chinese construction workers (Al-Sabah \& Refaat, 2019; Mohammadi, Tavakolan, \& Khosravi, 2018). The competent construction Department of the Chinese government is trying to vigorously promote the application of the OHS management system, and grass-root construction workers need reasonable and effective training methods. Therefore, it is necessary to explore the main factors affecting safety and improve the training effect in combination with the actual situation of the construction industry.

OHS management means that the organization adopts a coordinated and systematic approach to achieve sustainable improvement and dynamic, systematic, and institutionalized prevention-oriented management through the effective operation of the OHS management system. The products and services provided meet the requirements of relevant national laws and regulations on occupational health (Başağa, Temel, Atasoy, \& Yıldırım, 2018). OHS risk management is an important stage in the management process (H. Lingard \& Holmes, 2001). OHS management has been gradually applied in the related affairs of the construction 
industry. It is of great significance to the health and safety of construction workers $(\mathrm{H}$. Lingard \& Yesilyurt, 2003; Trethewy, 2003).

\section{LITERATURE REVIEW}

Therefore, the OHS management system is the premise of management standardization, and OHS are some of the key points of enterprise management (Aristide, Daniels-Jerome, \& Cadet, 2021). Earlier studies on occupational injuries and OHS factors in small enterprises showed that the increasing use of personal protective devices could improve safety (Bull, Riise, \& Moen, 2002), and that construction enterprise carried out different levels of safety education and training (Agumba \& Haupt, 2018; Arturo Hernandez-Arriaza, Perez-Alonso, Gomez-Galan, \& Salata, 2018; Cunningham \& Sinclair, 2015). One of the main risk factors in the construction industry is falling from height (Kaskutas, Dale, Lipscomb, \& Evanoff, 2013; Kaskutas et al., 2010), and suicide caused by psychological factors (King et al., 2019; King et al., 2018). With the development of intelligent monitoring technology, virtual technology is gradually popularized and applied (Hai Chien, Dao, Kim, Cho, \& Park, 2018; Wang, Wu, Wang, Chi, \& Wang, 2018). The precise construction and traditional dynamic principle are applied to improve construction safety (Wu, Yuan, Wang, Li, \& Wu, 2019). Current research on OHS in the construction industry mainly focuses on project stakeholders and materials $(\mathrm{H}$. C. Lingard, Cooke, \& Blismas, 2012), construction workers' physical diseases and occupational health service activities (Madgwick, Houdmont, \& Randall, 2011; Minna \& Mika, 2012), and construction workers' psychosocial working environment and mental health 
(Boschman, van der Molen, Sluiter, \& Frings-Dresen, 2013) including language barriers and cultural differences (Roelofs, Sprague-Martinez, Brunette, \& Azaroff, 2011). In recent years, although it is systematic and citation network analysis of OHS issues in operation management (Fan, Lo, Ching, \& Kan, 2014), it is recommended that safety professionals should take targeted group safety interventions, and pay attention to the mental health of personnel (He, McCabe, Jia, \& Sun, 2020), studies on the impact of an attitude toward safety training in the construction industry (Loosemore \& Malouf, 2019), and studies on the occupationally injured workers in the construction industry (Hoła \& Szóstak, 2017). As there are many influencing factors of OHS training, finding out the main influencing factors is the key to improve the effectiveness of training. It can be seen that, in view of the main influencing factors, managers should formulate effective measures to strengthen training and improve the risk awareness and safety level of construction workers.

According to the research literature on the application of the OHS management system in the construction industry, strengthening on-the-job learning and training, attaching importance to the research of operation process and technology, and preventing the research of risk influencing factors are the main measures of OHS risk management (Chen \& Cao, 2019). It can be seen that OHS training is the research focus of safety training in the construction industry at home and abroad (Ochs, Neis, Cullen, \& McGuinness, 2021). However, at present, there are few studies on the training effect of the OHS management system for construction workers in developing countries and even fewer studies on the actual situation of China's construction industry (Başağa et al., 2018). Therefore, it is necessary to analyze the effect and influencing factors of the OHS training system in China's construction 
industry and explore the strategies and methods to improve the effectiveness of OHS training in China's construction industry.

Based on the current situation of OHS training in China's construction industry, this study carried out corresponding investigation and research to find out the factors affecting the effectiveness of OHS training and then explored ways and methods to improve the effectiveness of OHS training. On the basis of understanding the current situation of OHS in the global construction industry (Lucchini \& London, 2014; Ramos, McGinley, \& Carlo, 2021), taking the effect of OHS training on construction sites in China as the object, the qualitative analysis and research results were obtained by using the methods of the questionnaire survey and decision tree intelligent discriminant analysis, so as to provide countermeasures for the application of OHS management system in OHS training of Chinese construction industry (Sousa, Almeida, \& Dias, 2014).

To sum up, based on cart discriminant analysis, this paper adds superposition comprehensive analysis method, and then puts forward a set of CAMF model, which fills a certain research gap on the basis of predecessors.

\section{METHODS}

In this study, the authors used statistical methods and survey forms as data acquisition tools. This questionnaire contains 22 questions related to OHS training (including 21 multiple-choice questions and one open-ended suggestion question). In the academic meeting of the advisory team, 25 topics were preliminarily chosen. After consulting advisors and 
training and technical experts, 22 questions were finalized. Then 10 construction workers were preliminarily surveyed, and the answer options were modified to form a formal survey questionnaire. The questionnaire was designed and a survey was conducted from December 2018 to May 2019.

To ensure the representativeness of the questionnaire survey, 258 workers in 10 construction projects from four representative regions (provinces) of China, namely East China (Shandong Province), South China (Hainan Province), central China (Hubei Province), North China (Hebei Province) were randomly interviewed face-to-face, 239 valid questionnaires were formed, and frequency analysis and relevant scores were conducted for the valid questionnaires Analysis, cross table and chi-square analysis (analysis software IBM SPSS 23). According to the plan made by the statistical level of the number of workers, the obtained data are evaluated by a descriptive method, and the data are determined by statistical analysis. First of all, the frequency table is used to describe frequency distribution. The detailed information of the data is analyzed and the frequency distribution of the data is analyzed. Then cross table and chi-square tests were used to analyze whether there was a significant relationship between categorical variables. Then, correlation analysis, decision tree intelligent discriminant analysis, and comprehensive analysis are used to determine the relationship between variables.

The variables used in this study are described in Table 1. 
Table 1. Variables/Category of Variables

\begin{tabular}{|c|l|}
\hline Codes & \multicolumn{1}{c|}{ Variables } \\
\hline C & Your gender \\
\hline D & Your age \\
\hline E & Your level of education \\
\hline F & Your marital status \\
\hline G & Your job type \\
\hline H & Do you have a vocational skill certificate \\
\hline I & Your cumulative working life in the construction industry \\
\hline J & About the number of working days per week \\
\hline K & How many hours do you work per day \\
\hline L & How do you acquire your job skills and knowledge \\
\hline M & Your job satisfaction \\
\hline N & Have you worked in other industries \\
\hline O & Do you often pay attention to information \\
\hline P & Have you ever experienced an accident \\
\hline Q & Have you ever witnessed an accident \\
\hline S & Have you received occupational health and safety (OHS) training \\
\hline Have you received other related training \\
\hline When have you recently received occupational \\
\hline What do you think is the effect of recent occupational training \\
\hline
\end{tabular}




\begin{tabular}{|c|l|}
\hline $\mathrm{V}$ & $\begin{array}{l}\text { How do you think OHS training or other related training is more } \\
\text { appropriate }\end{array}$ \\
\hline $\mathrm{W}$ & Occupational health and safety training or other related training plays a \\
& role in job responsibility \\
\hline $\mathrm{X}$ & Do you have any other suggestions \\
\hline
\end{tabular}

The CAMF model used in this study is shown in Figure 1, The analysis process is divided into five steps: frequency analysis, cross table, and chi-square analysis, related factor analysis, decision tree intelligent discriminant analysis, and comprehensive analysis. The purpose of each step analysis is to find the main influencing factors or important factors. Finally, the factors found in all steps are synthesized to obtain the final influencing factors needed in this study. Finally, the results are analyzed according to these factors.

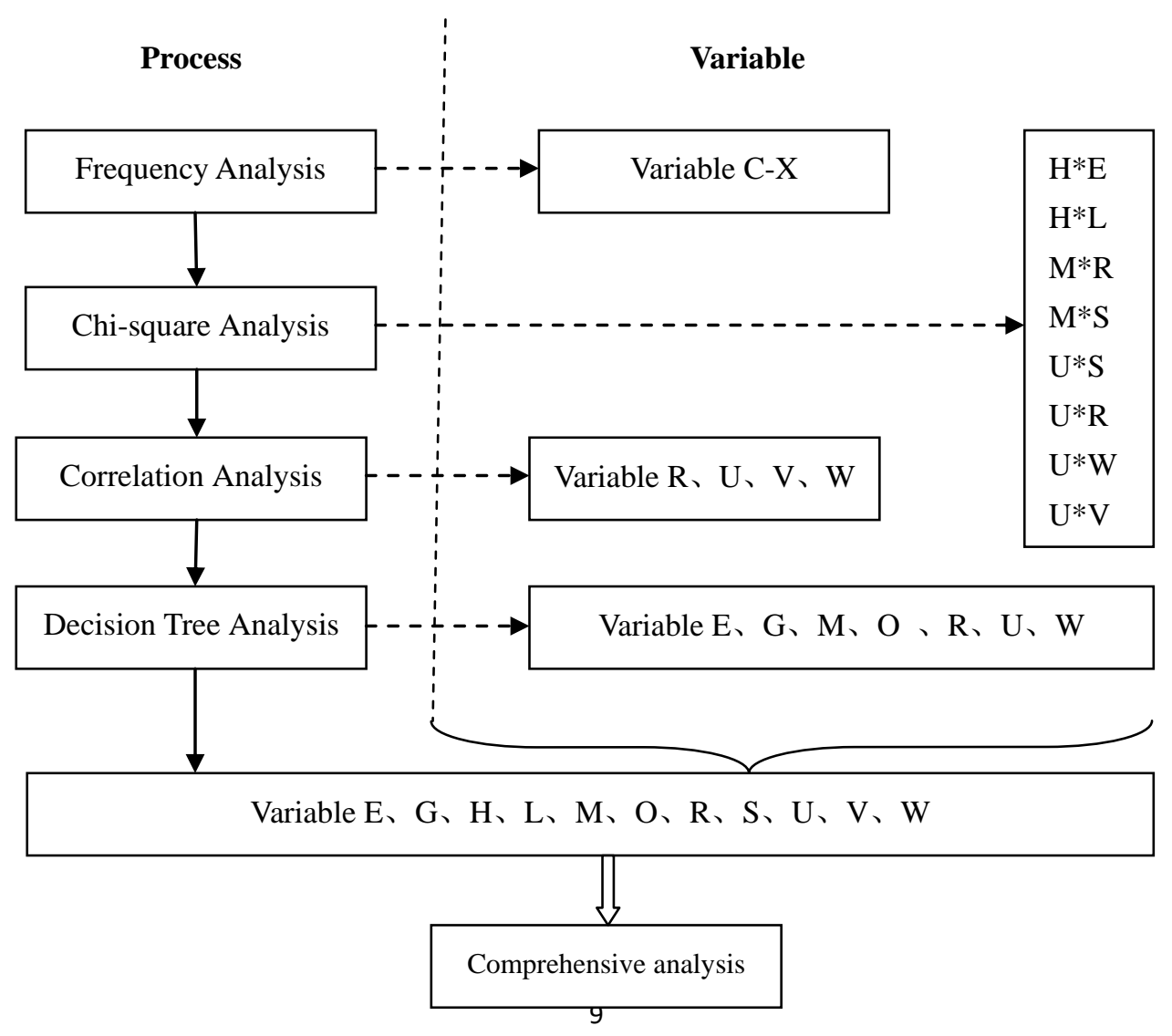




\section{Figure 1 CAMF Model}

\section{RESULTS}

Firstly, the frequency distribution of some data closely related to this study was analyzed, and then the cross table and chi-square test results were used to determine whether there was a significant relationship between the explanatory binary variables. Then the correlation analysis was used to find out the correlation variables with a Spearman correlation coefficient greater than 0.2 and describe the correlation between variables.

\subsection{Frequency Analysis}

The main variables are analyzed as follows (see Table A1. in Appendix A). The variable $\mathrm{D}$ is age, with a frequency of $1.7 \%$ for D1: Under 18 years old, the frequency of $12.1 \%$ for D2:18-29 years old, the frequency of $25.9 \%$ for D3: $30-39$ years old, the frequency of $35.6 \%$ for D4: 40-49 years old, the frequency of $23.4 \%$ for D5: $50-59$ years, and the frequency of 1.3\% for D6: 60 years old and over. The category D4 has the largest frequency with the category D1 having the smallest frequency indicating that workers aged 40-49 account for the majority, which is understandable as hiring workers under 18 is restricted under local legal protection restrictions and the proportion of workers over 60 is also very low. During the formal survey process, some managers expressed concerns about the legitimacy problems to hire these two groups of works which implies that employers do not employ these two types 
of workers.

The variable E is the level of education. For category E1: Primary school, frequency is 19.7\%. For category E2: junior high school, frequency is 54.0\%. For category E3: high school, frequency is $18.8 \%$. For category E4: secondary school, frequency is $5.4 \%$ For category E5: junior college, frequency is $0.8 \%$. For category E6: college and above, frequency is $1.3 \%$. The frequency of E2 is the largest, followed by E1, while the frequency of E5 and E6 are smaller. Junior high school and Primary school account for a larger proportion, while junior college and college and above account for a smaller proportion, indicating that the proportion of highly educated workers in the project site is low.

The variable $\mathrm{G}$ is job type. For G1: Woodworking, frequency is $30.5 \%$. For G2: reinforcing steel, frequency is $19.7 \%$. For G3: concrete, frequency is $10.5 \%$. For G4: masonry, frequency is $7.5 \%$. For G5: painter or decorator, frequency is 6.3\%. For G6: electrician, frequency is $5.9 \%$. For G7: plumber, frequency is $5.0 \%$. For G8: repairman, frequency is $5.0 \%$. For G9: tower, crane (hoist), outdoor elevator signaller, the frequency is $8.8 \%$. For G10: other types of work, the frequency is $4.2 \%$. The sum of frequency values of G1, G2, and G3 is $60.7 \%$, indicating that Woodworking, reinforcing steel, and concrete account for the majority of workers.

The variable $\mathrm{H}$ is Do you have a vocational skill certificate. For H1: Yes, the frequency is $38.9 \%$. For H2: No the frequency is $61.1 \%$. This indicates that the proportion of workers with qualification certificates is low.

The variable $\mathrm{K}$ is How many hours do you work per day. $\mathrm{K} 1$ is Less than 5 hours and frequency is $0.8 \%$. $\mathrm{K} 2$ is $5-6$ hours and frequency is $7.5 \%$. $\mathrm{K} 3$ is $6-7$ hours and frequency is 
$32.2 \%$. K4 is $9-10$ hours and frequency is $48.1 \%$. K5 is more than 10 hours and frequency is 11.3\%. The frequency value of variable $\mathrm{K} 4$ is the largest, and the sum of $\mathrm{K} 3$ and $\mathrm{K} 4$ frequency value is $80.3 \%$. It shows that the proportion of workers working $9-10$ hours a day is the largest, and the proportion of workers working 6-10 hours a day is $80.3 \%$.

The variable L is How do you acquire your job skills and knowledge. L1 is Vocational training and frequency is $13.4 \%$. L2 is apprenticeship and frequency is $70.3 \%$. L3 is self-study and frequency is $12.6 \%$. L4 is other ways and frequency is $3.8 \%$. The frequency value of variable L2 is the largest and L4 frequency value is the smallest, which indicates that the most common way for construction workers to acquire skills is through apprenticeship, which can be regarded as a traditional way of skill teaching in China.

The variable $\mathrm{M}$ is job satisfaction. $\mathrm{M} 1$ is highly satisfied and frequency is $34.7 \%$. M2 is a relatively satisfied frequency is $59.0 \%$. M3 is a Dissatisfied frequency is $6.3 \%$. The satisfaction rate of on-site workers to the current job is relatively high, while the unsatisfactory rate is the lowest, which is only $6.3 \%$.

The variable $\mathrm{O}$ is Do you often pay attention to information. $\mathrm{O} 1$ is Yes and the frequency is $51.5 \%$. $\mathrm{O} 2$ is No and the frequency is $48.5 \%$. It can be seen that the proportions of workers in the two conditions are not very different.

The variable $\mathrm{R}$ is Have you received occupational health and safety (OHS) training. R1 is Yes with a frequency of $49.4 \%$ and R2 is No with the frequency of $50.6 \%$. It can be seen that the proportion of receiving OHS training is close to that of not receiving OHS training. 
The variable $\mathrm{S}$ is Have you received other related training and $\mathrm{S} 1$ is Yes with the frequency of $54.0 \%$ and S2 is No with the frequency of $46.0 \%$. It can be seen that the proportion of receiving other related training is similar.

The variable $\mathrm{T}$ is When you have recently received occupational.T1 is 1 month ago and its frequency is $20.9 \%$.T2 is 3 months ago and its frequency is $26.8 \%$. T3 is 6 months ago and its frequency is $29.3 \%$. T4 is 1 year ago and its frequency is $23.0 \%$. It can be seen that the proportion of on-site workers receiving the latest training in each period is the same.

The variable $\mathrm{U}$ is What do you think is the effect of recent occupational training. $\mathrm{U} 1$ is Very Good with a frequency of $18.0 \%$. U2 is good with a frequency of $38.5 \%$. U3 is medium with a frequency of $42.3 \%$. U4 is poor with a frequency of $0.4 \%$. U5 is Very poor with a frequency of $0.8 \%$. The frequency value of $\mathrm{U} 3$ is the largest, and the sum of $\mathrm{U} 1, \mathrm{U} 2$, and $\mathrm{U} 3$ frequency value is $98.8 \%$. It can be seen that nearly all workers on the spot think OHS and related vocational training are effective.

The variable $\mathrm{V}$ is How do you think OHS training or other related training is more appropriate. V1 is a face-to-face explanation with a frequency of $33.9 \%$. V2 is audio-visual teaching with a frequency of $22.2 \%$. V3 is practical teaching with a frequency of $41.4 \%$. V4 is other ways with a frequency of $2.5 \%$. The frequency value of $\mathrm{V} 3$ is the largest, the frequency value of $\mathrm{V} 1, \mathrm{~V} 2, \mathrm{~V} 3$ is not very different and the sum of the three is $97.5 \%$. This shows that the most appropriate training methods that workers on the spot think are face-to-face, audio-visual, and practical.

The variable $\mathrm{W}$ is Occupational health and safety training or other related training plays a role in job responsibility.W1 is big and the frequency is $38.9 \%$. W2 is not big and the 
frequency is $21.3 \%$. W3 is medium and the frequency is $39.7 \%$. The sum of $\mathrm{W} 1$ and $\mathrm{W} 3$ frequencies is $78.6 \%$. It can be seen that in the opinion of the workers' OHS and related training play an important role in the job responsibility of workers on the spot.

The variable $X$ is Do you have any other suggestions (see Table A2. in Appendix A). X1 is NA and the frequency is $77.0 \%$. X2 is an added salary. and the frequency is $0.4 \%$. X3 is Give more guidance and help to workers and the frequency is $0.4 \%$. X4 is I am satisfied with this survey and hope that there will be more similar surveys in the future and the frequency is $0.4 \%$, change. X5 is NO and the frequency is $20.1 \%$. X6 is NO (Welder) and the frequency is 0.4\%. X7 is Physical examination and the frequency is $0.8 \%, \mathrm{X} 8$ is Regular training and learning and the frequency is $0.4 \%$. Because the variable $\mathrm{X}$ is an open question, option $\mathrm{X} 1$ is empty, that is, no answer, $\mathrm{X} 5$ is no answer, $\mathrm{X} 6$ is no answer (woodworking), and $\mathrm{X} 2, \mathrm{X} 3, \mathrm{X} 4$, $\mathrm{X} 7, \mathrm{X} 8$ are special suggestions from field workers, which should be paid attention to.

\subsection{Cross Table and Chi-square Analysis}

In order to explore whether there is a significant relationship between binary variables, cross table, and chi-square tests are used to analyze as follows (see Table 2). According to the chi-square test analysis of $\mathrm{H} * \mathrm{E}$ cross table and $\mathrm{H} * \mathrm{E}\left(\mathrm{X}^{2}=21.422\right.$, $\mathrm{P}$-value $\left.=.000\right)$, it can be seen that there is a significant relationship between H and E. Similarly, there are significant relationships between $\mathrm{H}$ and $\mathrm{L}, \mathrm{M}$ and $\mathrm{R}, \mathrm{M}$ and $\mathrm{S}, \mathrm{U}$ and $\mathrm{S}, \mathrm{U}$ and $\mathrm{R}, \mathrm{U}$ and $\mathrm{W}, \mathrm{U}$ and $\mathrm{V}$.

Table 2. Chi-Square Tests 


\begin{tabular}{|c|c|c|c|}
\hline Variable & $\mathrm{X}^{2}$ & P-value & \\
\hline $\mathrm{H}^{*} \mathrm{E}$ & 21.422 & .000 & Fisher's Exact Test \\
\hline $\mathrm{H}^{*} \mathrm{~L}$ & 56.932 & .000 & Fisher's Exact Test \\
\hline $\mathrm{M} * \mathrm{R}$ & 32.742 & .000 & Pearson Chi-Square \\
\hline $\mathrm{M} * \mathrm{~S}$ & 9.060 & .009 & Pearson Chi-Square \\
\hline $\mathrm{U} * \mathrm{~S}$ & 8.018 & .049 & Fisher's Exact Test \\
\hline $\mathrm{U} * \mathrm{R}$ & 25.049 & .000 & Fisher's Exact Test \\
\hline $\mathrm{U} * \mathrm{~W}$ & 66.228 & .000 & Fisher's Exact Test \\
\hline $\mathrm{U} * \mathrm{~V}$ & 34.857 & .002 & Fisher's Exact Test \\
\hline
\end{tabular}

\subsection{Correlation Analysis}

Referring to Table 1, combined with the above cross-table analysis and chi-square test, the following assumptions are put forward.

H1: Training effectiveness $(\mathrm{U})$ is positively correlated with whether or not OHS training $(\mathrm{R})$ is accepted.

$\mathrm{H} 2$ : Training effectiveness $(\mathrm{U})$ is positively correlated with training methods (V)

H3: Training Effectiveness (U) is positively correlated with Job Responsibility (W)

Table 3. shows that $\mathrm{U}^{*} \mathrm{R}$ 's Pearman's rho $=0.319, \mathrm{P}$-value $=0.000$ indicates a positive correlation between $\mathrm{U}$ and $\mathrm{R}$, so $\mathrm{H} 1$ is assumed to be valid. U*R's Pearman's rho $=0.261$, $\mathrm{P}$-value $=0.000$ indicates a positive correlation between $\mathrm{U}$ and $\mathrm{V}$, so $\mathrm{H} 2$ is assumed to be valid. $U^{*} \mathrm{~W}^{\prime}$ s Pearman's rho $=0.496, \mathrm{P}$-value $=0.000$ indicates a positive correlation between 
$\mathrm{U}$ and $\mathrm{W}$, so $\mathrm{H} 3$ is assumed to be valid.

Table 3. Crosstabulation

\begin{tabular}{|c|c|c|c|c|c|}
\hline \multicolumn{2}{|c|}{ Spearman's rho } & $\mathrm{R}$ & $\mathrm{U}$ & $\mathrm{V}$ & W \\
\hline \multirow[t]{2}{*}{$\mathrm{R}$} & $\begin{array}{l}\text { Correlation } \\
\text { Coefficient }\end{array}$ & 1.000 & & & \\
\hline & Sig. (2-tailed) & & & & \\
\hline \multirow[t]{2}{*}{$\mathrm{U}$} & $\begin{array}{l}\text { Correlation } \\
\text { Coefficient }\end{array}$ & $.319^{* *}$ & 1.000 & & \\
\hline & Sig. (2-tailed) & .000 & . & & \\
\hline \multirow[t]{2}{*}{ V } & $\begin{array}{l}\text { Correlation } \\
\text { Coefficient }\end{array}$ & -.043 & $.261^{* *}$ & 1.000 & \\
\hline & Sig. (2-tailed) & .509 & .000 & . & \\
\hline \multirow[t]{2}{*}{ W } & $\begin{array}{l}\text { Correlation } \\
\text { Coefficient }\end{array}$ & $.131^{*}$ & $.496^{* *}$ & $.158^{*}$ & 1.000 \\
\hline & Sig. (2-tailed) & .042 & .000 & .014 & \\
\hline
\end{tabular}

\subsection{Decision Tree Intelligent Discriminant Analysis}

Decision tree intelligent discriminant analysis method is a classification regression tree (CART) algorithm (Chrysos, Dagritzikos, Papaefstathiou, \& Dollas, 2013), which is widely used in medical diagnosis, biological analysis, deep learning, and optical application analysis, 
and also has many applications in data comparative analysis and classification importance analysis. In the engineering field, the CART decision tree is mainly used in equipment improvement, geotechnical engineering analysis, building damage assessment, and engineering modeling. The intelligent discriminant analysis of the decision tree has a large model capacity and wide application range. The target variable can be either a discrete variable or a continuous variable. It can also effectively deal with the problem of definite variables, and the model has the advantages of a clear hierarchy, strong readability, and comprehensibility. Therefore, this model is selected as the main analysis method of this empirical data (Zhang, 2013).

In this paper, all the options of the questionnaire are analyzed by using the decision tree model of SPSS. It is found that some variables can be constructed into the corresponding cart classification and regression tree. It should be noted that the decision tree generated by SPSS is simplified because this paper mainly studies the causal relationship among variables. For example, the variable $\mathrm{W}$ in Figure 2 is divided into two branches, $\mathrm{W}_{\mathrm{a}}$ and $\mathrm{W}_{\mathrm{b}}$, indicating that the sub-variables of $\mathrm{W}$ are divided into two categories, among which $\mathrm{W}_{\mathrm{b}}$ has two multi branches $\mathrm{O}_{\mathrm{a}}$ and $\mathrm{O}_{\mathrm{b}}$, and the branching meaning of other decision tree graphs is similar to this graph. For the training effectiveness (variable U), it can be seen from Figure 2 that the independent variable $\mathrm{W}$ in the first level of the decision tree model contributes the most to the dependent variable $\mathrm{U}$, and the independent variable $\mathrm{O}$ in the second level of the decision tree model contributes the most to the dependent variable $\mathrm{W}$. The risk estimation and standard error value of the measurement results (dependent variable $U$ ) of the prediction accuracy of the model are as follows Risk.Resubstitution.Std.Error=0.032( Risk.Resubstitution.Std. Error 
is abbreviated as RRSE), Risk.Cross-Validation.Std.Error $=0 \quad .032$

( Risk.Cross-Validation.Std.Error is abbreviated as VSRCE). The prediction accuracy is Classification.Overall-Percentage.Percent-Correct=56.5\%

( Classification.Overall-Percentage.Percent-Correct is abbreviated as COPPC).

Similarly, for the job responsibility (variable $\mathrm{W}$ ), the independent variable $\mathrm{U}$ in the first level of the decision tree model contributes the most to the dependent variable $\mathrm{W}$, and the risk estimation and standard error value of the measurement result (dependent variable W) of the prediction accuracy of the model are $\mathrm{RRSE}=0.032, \mathrm{RCVSE}=0.032$, and the prediction accuracy rate is COPPC $=60.3 \%$. For job satisfaction (variable $\mathrm{M}$ ), the independent variable $\mathrm{R}$ in the first level of the decision tree model contributes the most to the dependent variable $\mathrm{M}$, and the risk estimation and standard error value of the measurement result (dependent variable M) of the prediction accuracy of the model are $\operatorname{RRSE}=0.031$, RCVSE $=0.031$, and the prediction accuracy is COPPC $=64.0 \%$. For OHS training (variable R), the contribution of independent variable $\mathrm{M}$ to dependent variable $\mathrm{R}$ in the first level of the decision tree model is the largest, and the contribution of independent variable $\mathrm{K}$ to dependent variable $\mathrm{M}$ in the second level of the decision tree model is the largest. Moreover, the risk estimation and standard error value of the measurement results (dependent variable $\mathrm{R}$ ) of the prediction accuracy of the model were RRSE $=0.030, \operatorname{RCVSE}=0.031$, and the prediction accuracy rate was COPPC $=68.2 \%$. For education and age (variable E), the independent variable $\mathrm{D}$ in the first level of the decision tree model contributed the most to the dependent variable E. the risk estimation and a standard error value of the measurement results (dependent variable E) of the prediction accuracy of the model were $\operatorname{RSE}=0.032, \mathrm{RCVSE}=0.032$, and the prediction 
accuracy rate was COPPC $=54.0 \%$. For the work type (variable G), the independent variable $\mathrm{L}$ in the first level of the decision tree model contributes the most to the dependent variable $\mathrm{G}$, and the independent variable $\mathrm{S}$ contributes the most to the dependent variable $\mathrm{L}$ in the second level of the decision tree model. Moreover, the risk estimation and standard error value of the measurement results (dependent variable $G$ ) of the prediction accuracy of the model are $\mathrm{RRSE}=0.031, \mathrm{RCVSE}=0.031$, and the prediction accuracy rate is $\mathrm{COPPC}=38.5 \%$, which is not ideal. For information attention (variable $\mathrm{O}$ ), the independent variable $\mathrm{T}$ in the first level of the decision tree model contributes the most to dependent variable $\mathrm{O}$, and the independent variable $\mathrm{G}$ contributes the most to dependent variable $\mathrm{T}$ in the second level of the decision tree model. Moreover, the risk estimation and standard error value of the measurement results (dependent variable $\mathrm{O}$ ) of the prediction accuracy of the model are $\mathrm{RRSE}=0.027, \mathrm{RCVSE}=0.032$, and the prediction accuracy rate is $\mathrm{COPPC}=76.6 \%$.

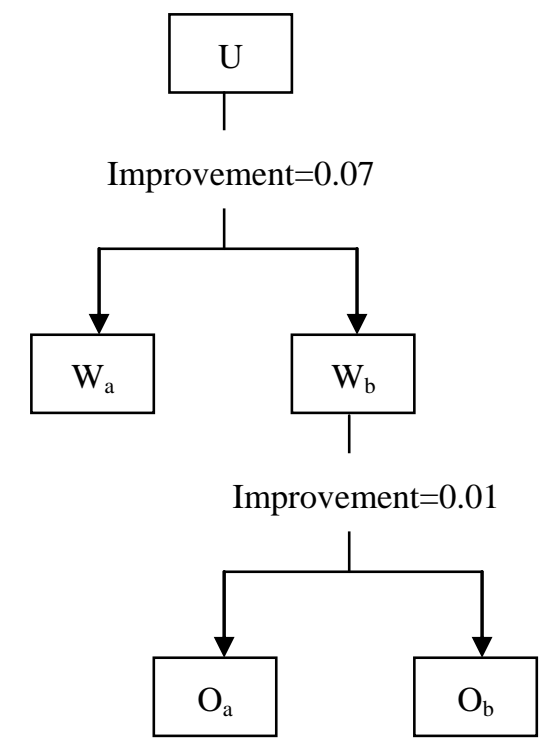

Figure 2 Decision Tree of Variable U 


\subsection{Comprehensive Analysis}

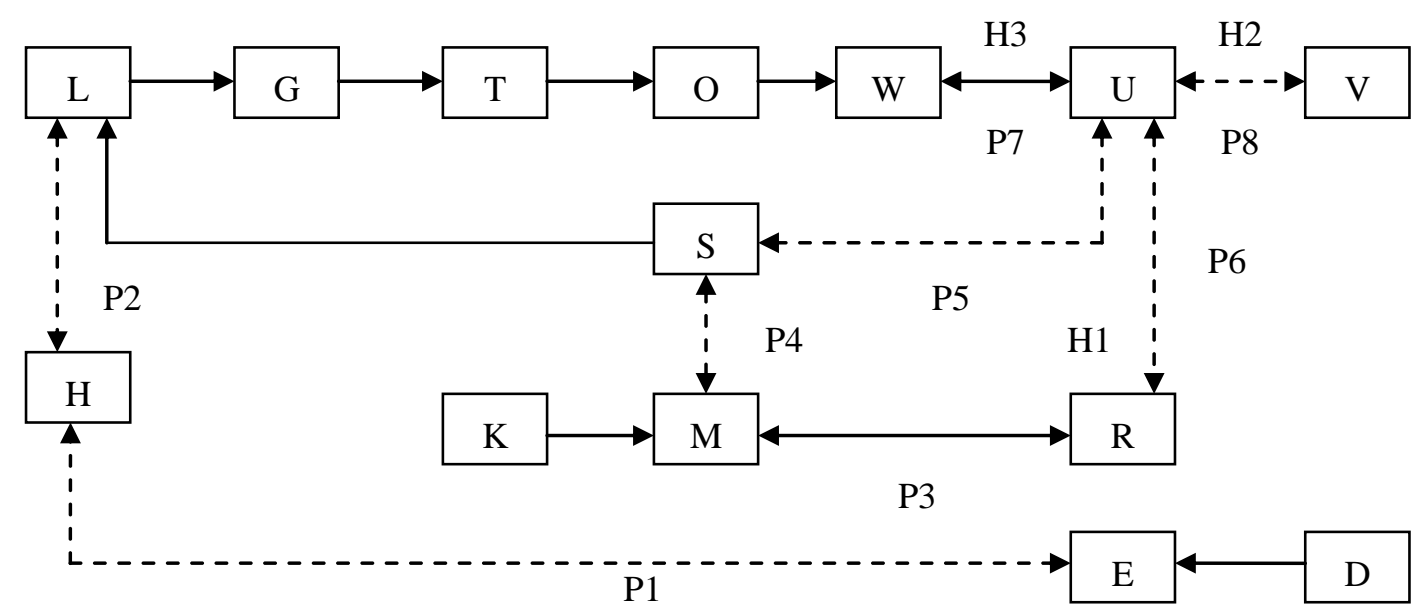

Figure 3 Logical Diagram

In combination with the above method model and analysis process, the found logical relations are analyzed as follows: first, the causal relations of variables in all decision trees are combined and linked with real arrow lines, in which double arrow lines represent mutual causal relations; secondly, virtual arrow lines represent eight groups of significant relations obtained from the cross table and chi-square analysis, represented by P1-P8; finally, the correlation of three groups of hypotheses is represented by H1, H2, H3.

There are 22 designed variables in this study, 14 of which appear in Figure 3 Logical diagram, among which 11 variables have a significant relationship in the cross table and chi-square analysis, and 3 variables (P3, P7, P8) have an overlapping causal relationship with a decision tree, and 2 variables $(\mathrm{H} 1, \mathrm{H} 2)$ have an overlapping causal relationship with decision tree; besides, 1 variable group has an overlapping causal relationship with decision 
tree in correlation analysis Item (H3). That is to say, there are 1 set of variable groups ( $\mathrm{U}$ and W) with a triple relationship in the logic diagram, and 2 sets of variable groups ( $\mathrm{U}$ and $\mathrm{V}, \mathrm{U}$, and R) with a double relationship. Moreover, from the quantitative analysis of the relationship between a single variable and other variables (expressed by $N_{i}, I$ is the variable name), $N_{U}=7$, $\mathrm{N}_{\mathrm{W}}=4, \mathrm{~N}_{\mathrm{L}}=3, \mathrm{~N}_{\mathrm{S}}=3, \mathrm{~N}_{\mathrm{M}}=3, \mathrm{~N}_{\mathrm{R}}=3$, and the number of other variable relationships is less than 3 .

In this way, according to the order that the overlapping relationship of variable groups takes precedence and the number of relationships involved in a single variable takes the second place, we found that the main factors of this questionnaire are $\mathrm{U}, \mathrm{W}, \mathrm{R}, \mathrm{V}, \mathrm{L}, \mathrm{S}, \mathrm{M}$. These factors and their correlation are also the main research objects of this study.

Through the above statistics and research analysis, the following results are obtained:

(1) At the same time, there is a significant relationship between educational background and qualification certificate, and the higher education background, the lower the proportion of qualified workers.

(2) Most of the skill acquisition methods of on-site workers are apprenticeship, and the most appropriate training methods are mainly practical training;

(3) The proportion of on-site workers receiving OHS training is close to that of other related training, and there is a significant relationship between their satisfaction with the current work and whether they have received safety training.

(4) Almost all on-site workers think that OHS and other related training are effective; OHS and other related training play a greater role in the job responsibilities of on-site workers. And the effectiveness of training is positively related to whether to accept OHS training, 
training methods, and post responsibility.

(5) On-site workers pay more attention to physical safety, training and learning, and future career development, with salary factors at the bottom.

\section{DISCUSSION}

Based on previous studies on OHS-related factors of construction workers (Başağa et al., 2018), this study conducted a one-to-one empirical survey on 239 workers from 10 projects in China's representative provinces. Based on the CART model and comprehensive analysis, this paper puts forward a set of the systematic analysis method to reveal the influencing factors of the effectiveness of OHS training for workers in construction enterprises, and proposes ways to improve the effectiveness of training.

The main contributions of this paper include the following three aspects: one is to improve the general application of individual statistical analysis methods in the past literature and form a set of comprehensive analysis logic path relationship diagrams. Through the comprehensive relationship analysis chart, we can directly see the causal relationship between the main factors and can count the overlapping times of the relationship path in a single major factor. The number of times indicates the importance of the factors. Although this method only makes a combination analysis of multiple factor analysis charts, there is no quantitative path calculation value. Secondly, this research method also improved the limitation of the SEM method on the design of Li's scale, so that the choice items of the scale can be set freely. The third is to propose appropriate ways to improve the effectiveness of training. 
The shortcomings of the model method constructed in this study need to be improved, mainly on the number of superposition of the relationship path needs manual statistics, for the model framework with many factors, it is not easy to accurately count. The later research plans to add a software algorithm to realize the automatic statistical function.

In addition, there are many ways to improve the safety problems of construction workers in China, such as safety training, system construction, execution, etc., but the implementation of OHS training is not strong enough. The survey shows that the proportion of OHS training is only 49.4\%. Therefore, the management should pay enough attention to it. The effectiveness of OHS training involves many factors. Enterprise managers should grasp the main factors to improve the efficiency of safety training. The effectiveness and main influencing factors of OHS training should also be combined with the government policy documents of different countries and regions, as well as in the different development stages of the construction market, taking corresponding measures and implementing dynamic adjustment of training methods.

\section{CONCLUSION}

The main research achievement of this paper is the field empirical method of a one-to-one questionnaire survey with high credibility. The analysis process of empirical data is divided into five steps: frequency analysis, cross table, and chi-square analysis, correlation factor analysis, cart decision tree intelligent discriminant analysis, and comprehensive analysis. Finally, the path map of comprehensive analysis relationship is constructed, and the 
CAMF model is proposed to explore how to improve and realize the effectiveness of OHS training for construction workers.

In view of the severe situation of safety and accident death in the construction industry, the main factors affecting the effectiveness of OHS training are further identified. Through the above analysis, the main conclusions are as follows.

- The construction industry needs to strengthen the OHS system training for the grass-root workers and carry out classified and graded training according to the workers' educational background, training methods, job satisfaction, and job responsibilities.

-In the safety training management of on-site workers, more attention should be paid to the factors of workers' physical safety, training and learning, and future career development.

- From the research, it is found that the comprehensive analysis method can be used to find out the main factors. And then combine them into a comprehensive analysis chart, which can directly see the causal relationship between the main factors and can count the number of overlapping times (importance) of the relationship path in a single main factor.

The research results of this paper can provide the corresponding countermeasures for the OHS training of China's construction industry, and also have a certain reference for the training in similar fields in other developing countries.

Data Availability Statement: All data, models, and code generated or used during the study appear in the submitted article.

Author Contributions: Conceptualization, Tao Chen; Data curation, Tao Chen and 
Zhonghong Cao; Formal analysis, Zhonghong Cao; Funding acquisition, Tao Chen; Investigation, Zhonghong Cao; Methodology, Tao Chen; Project administration, Tao Chen and Zhonghong Cao; Software, Zhonghong Cao; Supervision, Tao Chen; Validation, Tao Chen and Zhonghong Cao; Writing - original draft, Zhonghong Cao; Writing - review \& editing, Zhonghong Cao.

Funding: This study was funded by Key Soft Science Project of Hubei Science and Technology Support Plan (grant numbers 2015BDF006), National Social Science Project of Education Science 2017 (grant numbers BIA170192), and Key Open Fund Project of Hubei Industrial Policy and Management Research Center 2016-17 (grant numbers 17CYZ01).

Acknowledgments: The authors would like to acknowledge all the researchers who provided support, including Zhenggang Yao, Director of New Technology of New Eight Construction Group Co., Ltd., and Hui Yang, Project Manager of Wuhan Construction Engineering Third Construction Co., Ltd. for the support in the questionnaire survey, and Yuqing Cao, Department of Physics, Huazhong University of Science and Technology, for English language support.

Conflicts of Interest: The authors declare no conflict of interest.

\section{Appendix A}


Table A1. Nomenclature and frequency of the categories of Construction Site variables.

\begin{tabular}{|c|c|c|}
\hline $\begin{array}{c}\text { Variable/Category } \\
\text { Codes }\end{array}$ & Variables/Category of Variables & Frequency $(\%)$ \\
\hline $\mathbf{C}$ & Your gender & 100.0 \\
\hline $\mathrm{C} 1$ & Male & 87.9 \\
\hline $\mathrm{C} 2$ & Female & 12.1 \\
\hline $\mathbf{D}$ & Your age & 100.0 \\
\hline D1 & Under 18 years old & 1.7 \\
\hline D2 & 18-29 years old & 12.1 \\
\hline D3 & 30-39 years old & 25.9 \\
\hline D4 & 40-49 years old & 35.6 \\
\hline D5 & 50-59 years old & 23.4 \\
\hline D6 & 60 years old and over & 1.3 \\
\hline $\mathbf{E}$ & Your level of education & 100.0 \\
\hline E1 & Primary school & 19.7 \\
\hline E2 & junior high school & 54.0 \\
\hline
\end{tabular}

Table A1. Conts.

\begin{tabular}{ccc}
\hline Variable/Category & Variables/Category of Variables & Frequency (\%) \\
\hline E3 & senior high school & 18.8 \\
& 26 & \\
\hline
\end{tabular}




\begin{tabular}{|c|c|c|}
\hline $\mathrm{E} 4$ & secondary school & 5.4 \\
\hline E5 & junior college & .8 \\
\hline E6 & college and above & 1.3 \\
\hline $\mathbf{F}$ & Your marital status & 100.0 \\
\hline $\mathrm{F} 1$ & Unmarried & 6.7 \\
\hline $\mathrm{F} 2$ & Married & 88.3 \\
\hline F3 & Divorced & 4.6 \\
\hline $\mathrm{F} 4$ & Widowed & .4 \\
\hline G & Your job type & 100.0 \\
\hline G1 & Woodworking & 30.5 \\
\hline $\mathrm{G} 2$ & reinforcing steel & 19.7 \\
\hline G3 & concrete & 10.5 \\
\hline G4 & masonry & 7.5 \\
\hline G5 & painter or decorator & 6.3 \\
\hline G6 & electrician & 5.9 \\
\hline G7 & plumber & 5.0 \\
\hline G8 & repairman & 1.7 \\
\hline G9 & $\begin{array}{c}\text { tower,crane(hoist), outdoor elevator or } \\
\text { signaller }\end{array}$ & 8.8 \\
\hline G10 & other types of work & 4.2 \\
\hline
\end{tabular}

\section{Do you have a vocational skill}

H

certificate 


\begin{tabular}{|c|c|c|}
\hline $\mathrm{H} 1$ & Yes & 38.9 \\
\hline $\mathrm{H} 2$ & No & 61.1 \\
\hline \multicolumn{3}{|c|}{ Your cumulative working life in the } \\
\hline $\mathbf{I}$ & & 100.0 \\
\hline \multicolumn{3}{|c|}{ construction industry } \\
\hline I1 & less than one year & 3.3 \\
\hline $\mathrm{I} 2$ & $1-5$ years & 16.3 \\
\hline $\mathrm{I} 3$ & $6-10$ years & 25.1 \\
\hline $\mathrm{I} 4$ & $11-15$ years & 23.0 \\
\hline I5 & $16-20$ years & 15.1 \\
\hline I6 & more than 20 years & 17.2 \\
\hline & he number of worki & \\
\hline $\mathbf{J}$ & & 100.0 \\
\hline \multicolumn{3}{|c|}{ per week } \\
\hline $\mathrm{J} 1$ & less than 2 days & 1.3 \\
\hline $\mathrm{J} 2$ & 2 days & 5.0 \\
\hline $\mathrm{J} 3$ & 3 days & 3.3 \\
\hline $\mathrm{J} 4$ & 4 days & 13.8 \\
\hline J5 & 5 days & 26.8 \\
\hline J6 & more than 5 days & 49.8 \\
\hline
\end{tabular}

Table A1. Conts.

Variable/Category

\section{Codes}

Variables/Category of Variables $\quad$ Frequency (\%) 
How many hours do you work per

K

100.0

day

K1

Less than 5 hours

.8

K2

5-6hours

7.5

K3

6-7hours

32.2

K4

9-10 hours

48.1

K5

more than 10 hours

11.3

How do you acquire your job skills

L

100.0

and knowledge

\begin{tabular}{ccc}
\hline L1 & Vocational training & 13.4 \\
L2 & apprenticeship & 70.3 \\
L3 & self-study & 12.6 \\
L4 & other ways & 3.8 \\
\hline M & Your job satisfaction & $\mathbf{1 0 0 . 0}$ \\
M1 & Satisfaction & 34.7 \\
M2 & Comparative satisfaction & 59.0 \\
M3 & Dissatisfaction & 6.3 \\
\hline N & Have you worked in other industries & $\mathbf{1 0 0 . 0}$ \\
\hline $\mathrm{N} 1$ & I have worked in other industries & 51.5 \\
N2 & I have not worked in other industries & 48.5 \\
\hline
\end{tabular}

Do you often pay attention to

O

100.0

information 


\begin{tabular}{|c|c|c|}
\hline $\mathrm{O} 1$ & Yes & 43.9 \\
\hline $\mathrm{O} 2$ & No & 56.1 \\
\hline $\mathbf{P}$ & $\begin{array}{c}\text { Have you ever experienced an } \\
\text { accident }\end{array}$ & 100.0 \\
\hline P1 & I've experienced it myself & 18.4 \\
\hline $\mathrm{P} 2$ & I haven't experienced it myself & 81.6 \\
\hline $\mathbf{Q}$ & Have you ever witnessed an accident & 100.0 \\
\hline Q1 & Yes & 56.9 \\
\hline Q2 & No & 43.1 \\
\hline $\mathbf{R}$ & $\begin{array}{l}\text { Have you received occupational } \\
\text { health and safety (OHS) training }\end{array}$ & 100.0 \\
\hline $\mathrm{R} 1$ & Yes & 49.4 \\
\hline $\mathrm{R} 2$ & No & 50.6 \\
\hline $\mathbf{S}$ & $\begin{array}{c}\text { Have you received other related } \\
\text { training }\end{array}$ & 100.0 \\
\hline S1 & Yes & 54.0 \\
\hline $\mathrm{S} 2$ & No & 46.0 \\
\hline $\mathbf{T}$ & $\begin{array}{l}\text { When have you recently received } \\
\text { occupational }\end{array}$ & 100.0 \\
\hline $\mathrm{T} 1$ & 1 month ago & 20.9 \\
\hline $\mathrm{T} 2$ & 3 months ago & 26.8 \\
\hline $\mathrm{T} 3$ & 6 months ago & 29.3 \\
\hline
\end{tabular}


Table A1. Conts.

\begin{tabular}{|c|c|c|}
\hline $\begin{array}{l}\text { Variable/Category } \\
\text { Codes }\end{array}$ & Variables/Category of Variables & Frequency $(\%)$ \\
\hline $\mathrm{T} 4$ & 1 year ago & 23.0 \\
\hline $\mathbf{U}$ & $\begin{array}{l}\text { What do you think is the effect of } \\
\text { recent occupational training }\end{array}$ & 100.0 \\
\hline U1 & Very Good & 18.0 \\
\hline $\mathrm{U} 2$ & good & 38.5 \\
\hline $\mathrm{U} 3$ & medium & 42.3 \\
\hline $\mathrm{U} 4$ & poor & .4 \\
\hline U5 & Very poor & .8 \\
\hline & How do you think OHS training or & \\
\hline $\mathbf{V}$ & $\begin{array}{c}\text { other related training is more } \\
\text { appropriate }\end{array}$ & 100.0 \\
\hline V1 & face-to-face explanation & 33.9 \\
\hline $\mathrm{V} 2$ & audio-visual teaching & 22.2 \\
\hline $\mathrm{V} 3$ & practical teaching & 41.4 \\
\hline V4 & other ways & 2.5 \\
\hline & Occupational health and safety & \\
\hline $\mathbf{W}$ & $\begin{array}{l}\text { training or other related training } \\
\text { plays a role in job responsibility }\end{array}$ & 100.0 \\
\hline
\end{tabular}




\begin{tabular}{|c|c|c|}
\hline W1 & Big & 38.9 \\
\hline W2 & not big & 21.3 \\
\hline W3 & medium & 39.7 \\
\hline $\mathbf{X}$ & Do you have any other suggestions & 100.0 \\
\hline $\mathrm{X} 1$ & & 77.0 \\
\hline $\mathrm{X} 2$ & add salary & .4 \\
\hline \multirow[t]{2}{*}{$\mathrm{X} 3$} & Give more guidance and help to workers & .4 \\
\hline & I am satisfied with this survey and hope & \\
\hline \multirow[t]{2}{*}{$\mathrm{X} 4$} & that there will be more similar surveys & .4 \\
\hline & in the future. & \\
\hline $\mathrm{X} 5$ & NO & 20.1 \\
\hline X6 & NO ( Welder ) & .4 \\
\hline $\mathrm{X} 7$ & Physical examination & .8 \\
\hline $\mathrm{X} 8$ & Regular training and learning & .4 \\
\hline
\end{tabular}

Table A2. Suggested Sorting Table

\begin{tabular}{ccc}
\hline $\begin{array}{c}\text { Variable/Category } \\
\text { Codes }\end{array}$ & Variables/Category of Variables & Frequency $(\boldsymbol{\%})$ \\
\hline $\mathbf{X}$ & Do you have any other suggestions & $\mathbf{1 0 0 . 0}$ \\
\hline X1 & NO & 77.0 \\
X5 & Physical examination & 20.1 \\
X7 & .8
\end{tabular}


X8

X6

Regular training and learning

.4

.4

I am satisfied with this survey and hope

$\mathrm{X} 4$

that there will be more similar surveys

.4

in the future.

X3

Give more guidance and help to workers

.4

$\mathrm{X} 2$ add salary

\section{REFERENCES}

Agumba, J. N., \& Haupt, T. C. (2018). The influence of health and safety practices on health and safety performance outcomes in small and medium enterprise projects in the South African construction industry. Journal of the South African Institution of Civil Engineering, 60(3), 61-72. doi:10.17159/2309-8775/2018/v60n3a6

Al-Sabah, R., \& Refaat, O. (2019). Assessment of construction risks in public projects located in the state of Kuwait. Journal of Engineering Research, 7(3), 13-32. Retrieved from $<$ Go to ISI $>$ ://WOS:000479141200002

Al-Salahi, K. F., Naji, K. K., \& Gunduz, M. (2020). Evaluation of the Critical Success Factors (CSFs) in Selecting Building Contractors Using Pareto Analysis and the Analytical Hierarchy Process. Journal of Engineering Research, 8(4), 1-15. Retrieved from <Go to ISI >://WOS:000592269600001

Aristide, S., Daniels-Jerome, L., \& Cadet, M. J. (2021). Healthy People 2030: Occupational 
Health Nurse Understanding Osteoporosis Objective of Prevention and Treatment. Workplace health \& safety, 69(7), 344-344. doi:10.1177/21650799211017328

Arturo Hernandez-Arriaza, F., Perez-Alonso, J., Gomez-Galan, M., \& Salata, F. (2018). The Guatemalan Construction Industry: Approach of Knowledge Regarding Work Risks Prevention. International Journal of Environmental Research and Public Health, 15(10). doi:10.3390/ijerph15102252

Başağa, H. B., Temel, B. A., Atasoy, M., \& Yıldırım, İ. (2018). A study on the effectiveness of occupational health and safety trainings of construction workers in Turkey. Safety Science, 110, 344-354. doi:https://doi.org/10.1016/j.ssci.2018.09.002

Boschman, J. S., van der Molen, H. F., Sluiter, J. K., \& Frings-Dresen, M. H. W. (2013). Psychosocial work environment and mental health among construction workers. Applied Ergonomics, 44(5), 748-755. doi:https://doi.org/10.1016/j.apergo.2013.01.004

Bull, N., Riise, T., \& Moen, B. E. (2002). Work-related injuries and occupational health and safety factors in smaller enterprises--a prospective study. Occupational medicine (Oxford, England), 52(2), 70-74. doi:10.1093/occmed/52.2.70

Chen, T., \& Cao, Z. (2019). Overview of research literature on OHS management system in construction industry. Paper presented at the 7th International Symposium on Project Management, ISPM 2019, July 6, 2019, Chongqing, China.

Chrysos, G., Dagritzikos, P., Papaefstathiou, I., \& Dollas, A. (2013). HC-CART: A Parallel System Implementation of Data Mining Classification and Regression Tree (CART) Algorithm on a Multi-FPGA System. Acm Transactions on Architecture and Code Optimization, 9(4). doi:10.1145/2400682.2400706 
Cunningham, T. R., \& Sinclair, R. (2015). Application of a model for delivering occupational safety and health to smaller businesses: Case studies from the US. Safety Science, 71, 213-225. doi:10.1016/j.ssci.2014.06.011

Fan, D., Lo, C. K. Y., Ching, V., \& Kan, C. W. (2014). Occupational health and safety issues in operations management: A systematic and citation network analysis review. International Journal of Production Economics, 158, 334-344. doi:https://doi.org/10.1016/j.ijpe.2014.07.025

Guo, S., He, J., Li, J., \& Tang, B. (2020). Exploring the Impact of Unsafe Behaviors on Building Construction Accidents Using a Bayesian Network. International Journal of Environmental Research and Public Health, 17(1). doi:10.3390/ijerph17010221

Hai Chien, P., Dao, N.-N., Kim, J.-U., Cho, S., \& Park, C.-S. (2018). Energy-Efficient Learning System Using Web-Based Panoramic Virtual Photoreality for Interactive Construction Safety Education. Sustainability, 10(7). doi:10.3390/su10072262

He, C., McCabe, B., Jia, G., \& Sun, J. (2020). Effects of Safety Climate and Safety Behavior on Safety Outcomes between Supervisors and Construction Workers. Journal of $\begin{array}{lll}\text { Construction } \quad \text { Engineering } & \text { Management, }\end{array}$ doi:10.1061/(asce)co.1943-7862.0001735

Hoła, B., \& Szóstak, M. (2017). An Occupational Profile of People Injured in Accidents at Work in the Polish Construction Industry. Procedia Engineering, 208, 43-51. doi:https://doi.org/10.1016/j.proeng.2017.11.019

Kaskutas, V., Dale, A. M., Lipscomb, H., \& Evanoff, B. (2013). Fall prevention and safety communication training for foremen: report of a pilot project designed to improve 
residential construction safety. Journal of safety research, 44, 111-118. doi:10.1016/j.jsr.2012.08.020

Kaskutas, V., Dale, A. M., Lipscomb, H., Gaal, J., Fuchs, M., Evanoff, B., \& Carpenters' Joint Apprenticeship Program Instructor, T. (2010). Changes in fall prevention training for apprentice carpenters based on a comprehensive needs assessment. Journal of safety research, 41(3), 221-227. doi:10.1016/j.jsr.2010.01.006

King, T. L., Batterham, P. J., Lingard, H., Gullestrup, J., Lockwood, C., Harvey, S. B., . . . Milner, A. (2019). Are Young Men Getting the Message? Age Differences in Suicide Prevention Literacy among Male Construction Workers. International Journal of Environmental Research and Public Health, 16(3). doi:10.3390/ijerph16030475

King, T. L., Gullestrup, J., Batterham, P. J., Kelly, B., Lockwood, C., Lingard, H., . . Milner, A. (2018). Shifting Beliefs about Suicide: Pre-Post Evaluation of the Effectiveness of a Program for Workers in the Construction Industry. International Journal of Environmental Research and Public Health, 15(10). doi:10.3390/ijerph15102106

Lei, Z., Tang, W., Duffield, C. F., Zhang, L., Hui, F. K. P., \& You, R. (2018). Qualitative Analysis of the Occupational Health and Safety Performance of Chinese International Construction Projects. Sustainability, 10(12). doi:10.3390/su10124344

Lingard, H., \& Holmes, N. (2001). Understandings of occupational health and safety risk control in small business construction firms: barriers to implementing technological controls. Construction Management \& Economics, 19(2), 217-226. doi:10.1080/01446190010002570

Lingard, H., \& Yesilyurt, Z. (2003). The Effect of Attitudes on the Occupational Safety 
Actions of Australian Construction Workers: The Results of a Field Study. Journal of Construction Research, 4(1), 59. Retrieved from http://search.ebscohost.com/login.aspx?direct=true \&db=buh\&AN=9209343\&lang=zh $\underline{\text {-cn\&site }=\text { ehost-live }}$

Lingard, H. C., Cooke, T., \& Blismas, N. (2012). Designing for construction workers' occupational health and safety: a case study of socio-material complexity. Construction Management \& Economics, 30(5), 367-382. doi:10.1080/01446193.2012.667569

Loosemore, M., \& Malouf, N. (2019). Safety training and positive safety attitude formation in the Australian construction industry. Safety Science, 113, 233-243. doi:10.1016/j.ssci.2018.11.029

Lucchini, R. G., \& London, L. (2014). Global Occupational Health: Current Challenges and the Need for Urgent Action. Annals of Global Health, 80(4), 251-256. doi:https://doi.org/10.1016/j.aogh.2014.09.006

Madgwick, P., Houdmont, J., \& Randall, R. (2011). Sun safety measures among construction workers in Britain. Occupational Medicine-Oxford, 61(6), 430-433. doi:10.1093/occmed/kqr054

Mei, Q., Wang, Q., Liu, S., Zhou, Q., \& Zhang, J. (2020). Effects of organizational safety on employees' proactivity safety behaviors and occupational health and safety management systems in Chinese high-risk small-scale enterprises. International Journal of Occupational Safety and Ergonomics, 26(1), 101-111. doi:10.1080/10803548.2018.1470287 
Minna, S., \& Mika, N. (2012). Relationship between construction workers' musculoskeletal disorders and occupational health service activities. Work, 41, 3753-3756. Retrieved from

http://search.ebscohost.com/login.aspx $?$ direct=true $\& d b=b u h \& A N=71928383\langle=z h-c n$ $\&$ site $=$ ehost-live

Mohammadi, A., Tavakolan, M., \& Khosravi, Y. (2018). Factors influencing safety performance on construction projects: A review. Safety Science, 109, 382-397. doi:https://doi.org/10.1016/j.ssci.2018.06.017

Ochs, C., Neis, B., Cullen, K., \& McGuinness, E. J. (2021). Occupational safety and health in marine aquaculture in Atlantic Canada: What can be learned from an analysis of provincial occupational injury compensation claims data? Aquaculture, 540. doi:10.1016/j.aquaculture.2021.736680

Qammaz, A. S. B., \& AlMaian, R. Y. (2020). A critical success factors model for effective implementation of risk management process in the construction projects. Journal of Engineering Research, 8(3), 50-70. Retrieved from <Go to ISI >://WOS:000592268600004

Ramos, A. K., McGinley, M., \& Carlo, G. (2021). The relations of workplace safety, perceived occupational stress, and adjustment among Latino/a immigrant cattle feedyard workers in the United States. Safety Science, 139. doi:10.1016/j.ssci.2021.105262

Roelofs, C., Sprague-Martinez, L., Brunette, M., \& Azaroff, L. (2011). A qualitative investigation of Hispanic construction worker perspectives on factors impacting 
worksite safety and risk. Environmental Health, 10. doi:10.1186/1476-069x-10-84

Sousa, V., Almeida, N. M., \& Dias, L. A. (2014). Risk-based management of occupational safety and health in the construction industry - Part 1: Background knowledge. Safety Science, 66, 75-86. doi:https://doi.org/10.1016/j.ssci.2014.02.008

Timofeeva, S. S., Ulrikh, D. V., \& Tsvetkun, N. V. (2017). Professional Risks in Construction $\begin{array}{lll}\text { Industry. } & \text { Procedia } & \text { Engineering, }\end{array}$ doi:https://doi.org/10.1016/j.proeng.2017.10.571

Tremblay, A., \& Badri, A. (2018). Assessment of occupational health and safety performance evaluation tools: State of the art and challenges for small and medium-sized $\begin{array}{llll}\text { enterprises. } & \text { Safety } & \text { Science, } & 101,\end{array}$ doi:https://doi.org/10.1016/j.ssci.2017.09.016

Trethewy, R. W. (2003). OHS Performance - Improved Indicators for Construction Contractors. Journal of Construction Research, 4(1), 17. Retrieved from http://search.ebscohost.com/login.aspx?direct=true\&db=buh\&AN=9209347\&lang=zh $\underline{\text {-cn\&site }=\text { ehost-live }}$

Wang, P., Wu, P., Wang, J., Chi, H.-L., \& Wang, X. (2018). A Critical Review of the Use of Virtual Reality in Construction Engineering Education and Training. International Journal of Environmental Research and Public Health, 15(6). doi:10.3390/ijerph15061204

Wu, X., Yuan, H., Wang, G., Li, S., \& Wu, G. (2019). Impacts of Lean Construction on Safety Systems: A System Dynamics Approach. International Journal of Environmental Research and Public Health, 16(2). doi:10.3390/ijerph16020221 
Zhang, W. (2013). Spss20.0 advanced course of statistical analysis (version 2). In H. E. Press (Ed.), (pp. 344-352). 